\title{
Hydrogenation of 1-octene by Co-Mo/MCM-41 catalysts
}

\author{
Chol Ryong JANG ${ }^{\mathrm{a}^{*}}$, Vasile MATEI ${ }^{\mathrm{b}}$, Anca BORCEA ${ }^{\mathrm{b}}$, Viorel VOICU ${ }^{\mathrm{b}}$, Raluca PROSCANU ${ }^{\mathrm{b}}$ and Dragos \\ CIUPARU $^{\mathrm{b} * *}$. \\ ${ }^{a}$ Department of Petroleum Processing Engineering, Faculty of Petroleum Technology, Hamhung University of \\ Chemical Industry, Str. Jongsong, Hamhung, D. P. R. of Korea \\ ${ }^{b}$ Department of Petroleum Processing Engineering and Environmental Protection, Faculty of Petroleum \\ Technology and Petrochemistry, Petroleum-Gas University of Ploieşti, Bd. Bucureşti 39, 100680, Ploieşti, \\ Romania
}

\begin{abstract}
The synthesis and characterization of MCM-41 supported Co-Mo catalysts and catalytic hydrogenation of 1-octene to n-octane were discussed. BET specific surface area of MCM-41, calculated from $\mathrm{N}_{2}$ adsorption/desorption isotherm, was $1690 \mathrm{~m}^{2} / \mathrm{g}$. The XRD patterns of the Co-Mo/MCM-41 catalysts show that metal species are finely dispersed and the size of $\mathrm{CoO}$ and $\mathrm{MoO}_{3}$ particles is below the detection limit by XRD. The 1-octene hydrogenation activity of the catalysts decreased with increasing the Co content up to 9 wt.\% for the Co-promoted Co-Mo/MCM-41 catalysts with a $\mathrm{MoO}_{3}$ content of $12 \mathrm{wt} \%$. All the catalysts show increased hydrogenation activity with increasing reaction temperature in the temperature range from 200 to $350^{\circ} \mathrm{C}$.
\end{abstract}

Keywords: 1-octene conversion, XRD, Co-Mo/MCM-41, BET specific surface area.

\section{Introduction}

It is well known that mesoporous materials such as MCM-41 and SBA-15 have many applications in chemical industry, petrochemistry, medicine, biosensors etc. In recent years, they are employed as adsorbents and supports of catalyst not only in organic synthesis, but also in petroleum refining [1, 2]. In petroleum refining, the hydrotreating process is an important unit. This process is widely used to removing sulfur containing compounds from gasoline, gas oil and heavier distillates. The removal of the sulfur containing compounds is necessary to meet the regulations for environmental protection and requires the use of catalysts with high performance. During the desulfurization by hydrotreatment, saturation of olefines in the gasoline by hydrogenation brings the loss of several octane numbers. Therefore, the hydrotreating process requires the use of catalysts with high hydrodesulfurization (HDS) performance, but with low olefine hydrogenation activity.
In petroleum refineries, $\gamma$-alumina supported molybdenum based catalysts promoted with Co or $\mathrm{Ni}$ have been used for the HDS of sulfur containing compounds [3]. It is well known that during hydrotreatment of petroleum products, different reactions occur depending on the nature of the feedstock, the catalysts used and the reaction conditions. Therefore, many investigations were dedicated to the synthesis of catalysts with better HDS performance. At present, various catalysts based on mesoporous materials are developed and tested for HDS performance $[4,5]$.

The purpose of this contribution is to studying the hydrogenation of 1-octene to n-octane by using MCM-41 supported Co-Mo catalysts. The nickelcatalyzed hydrogenation of 1-octene to n-octane has been already investigated by many researchers [6-8], but, to the best of our knowledge, the hydrogenation of 1-octene on MCM-41 supported catalysts has not been yet reported in the literature. We have therefore studied the performances of the MCM-41 supported Co-Mo catalysts in 1-octene hydrogenation reaction. 


\section{Experimental}

The synthesis of the MCM-41 used as support for Co-Mo catalyst was carried out in two steps: preparation of a surfactant $\mathrm{C}_{16}$ and synthesis of the mesoporous silica, using a method modified by Ciuparu et al. [9] that has been previously described in detail in literature $[1,2]$. For the preparation of the surfactant $\mathrm{C}_{16}$, cetyl-trimethyl-ammonium bromide $(\mathrm{CTAB})$ as a template and ion exchange resin Amberjet 4400 are used and tetramethylammonium silicate (TMAS) as silica source, fumed silica CabO-Sil M5, antifoam A and nitric acid are used for the synthesis of the silica.

The loading of the Co-Mo catalysts was carried out by incipient wetness impregnation of the synthesized MCM-41 sieve. Aqueous solutions of $\mathrm{Co}\left(\mathrm{NO}_{3}\right)_{2} \cdot 6 \mathrm{H}_{2} \mathrm{O}$ and $\left(\mathrm{NH}_{4}\right)_{6} \mathrm{Mo}_{7} \mathrm{O}_{24} \cdot 4 \mathrm{H}_{2} \mathrm{O}$ were used for the catalysts $\mathrm{Co}-\mathrm{Mo} / \mathrm{MCM}-41$. The obtained MCM-41 was impregnated first with the required amount of aqueous solution of $\left(\mathrm{NH}_{4}\right)_{6} \mathrm{Mo}_{7} \mathrm{O}_{24} \cdot 4 \mathrm{H}_{2} \mathrm{O}$ and dried at $120^{\circ} \mathrm{C}$ for $14 \mathrm{~h}$; the dried material was calcined at $450^{\circ} \mathrm{C}$ for $6 \mathrm{~h}$ and at $500^{\circ} \mathrm{C}$ for $2 \mathrm{~h}$ in air. Then, the Mo/MCM- 41 was impregnated with the required amount of $\mathrm{Co}\left(\mathrm{NO}_{3}\right)_{2} \cdot 6 \mathrm{H}_{2} \mathrm{O}$, also dried at $120^{\circ} \mathrm{C}$ and calcined at $450^{\circ} \mathrm{C}$ for $6 \mathrm{~h}$ and at $500^{\circ} \mathrm{C}$ for $2 \mathrm{~h}$ in air. In the case of Mo/MCM-41, $\mathrm{MoO}_{3}$ content was of 12 wt.\% and, in the case of Co$\mathrm{Mo} / \mathrm{MCM}-41$ catalyst, the promoted $\mathrm{CoO}$ content was varied at 3, 6 and 9 wt.\%, respectively. These catalysts are further refferet to as $\mathrm{Co}(3)$ Mo(12)/MCM-41, Co(6)-Mo(12)/MCM-41 and Co(9)-Mo(12)/MCM-41, respectively.

Nitrogen adsorbtion/desorbtion isotherms of the MCM-41 were measured at $-196^{\circ} \mathrm{C}$ with a static volumetric instrument Quantachrome Autosorb Automated Gas Sorption System using liquid nitrogen. Prior to the measurement, the sample was outgassed at $100^{\circ} \mathrm{C}$ for $30 \mathrm{~min}$ and at $200^{\circ} \mathrm{C}$ for $2 \mathrm{~h}$ to a residual pressure below $133.32 \times 10^{-10} \mathrm{MPa}$.

$\mathrm{X}$-ray diffraction (XRD) patterns were collected at ambient atmosphere by a Bruker D8 Advance diffractometer with $\mathrm{Cu} \mathrm{K}_{\alpha}$ radiation $\left(\lambda_{\mathrm{Cu}}=0.1541 \mathrm{~nm}\right.$, $40 \mathrm{kV}, 40 \mathrm{~mA}$ ). The XRD patterns of the MCM-41 and the MCM-41 supported Co-Mo catalysts were recorded at $2 \theta$ range of $1 \sim 6^{\circ}$ and $1 \sim 60^{\circ}$ with a step of $0.1^{\circ}$.
For measuring the catalytic performance of the synthesized Co-Mo catalysts, a fixed-bed flow microreactor with an inner diameter of $10 \mathrm{~mm}$ and $300 \mathrm{~mm}$ length was used. The catalyst bed of approximately $30 \mathrm{~mm}$ length was packed between two quartz wool layers in the center of the reactor. The reaction temperature was continuously measured with a thermocouple placed inside the reactor in the catalytic bed. For each activity tests, approximately $2 \mathrm{~g}$ of the Co-Mo/MCM-41 catalysts were used and a mixture of i-octane (88 wt.\%) and 1-octene (12 wt.\%) was taken as feedstock. The catalytic activity was tested from 200 to $350^{\circ} \mathrm{C}$, at $0.3 \mathrm{MPa}$ pressure and at liquid hourly space velocity (LHSV) of $8 \mathrm{~h}^{-1}$. The hydrogenation reaction products were quantitatively analyzed using a Varian 450-GC and 1-octene conversion was calculated from the analysis results.

\section{Results and Discussions}

Figure 1 shows nitrogen adsorption/desorption isotherms of the MCM-41. The isotherm exhibits the typical shape of type IV isotherm associated with MCM-41 mesoporous materials with finely ordered hexagonal structure.

Specific surface area of the MCM-41 was calculated using the BET equation:

$$
\frac{1}{V\left[\left(P_{0} / P\right)-1\right]}=\frac{C-1}{V_{m} C}\left(\frac{P}{P_{0}}\right)+\frac{1}{V_{m} C}
$$

where $V$ is weight of monolayer adsorbed gas, $P / P_{0}$ is relative pressure, $V_{m}$ is weight of adsorbate as monolayer, and $C$ is BET constant.

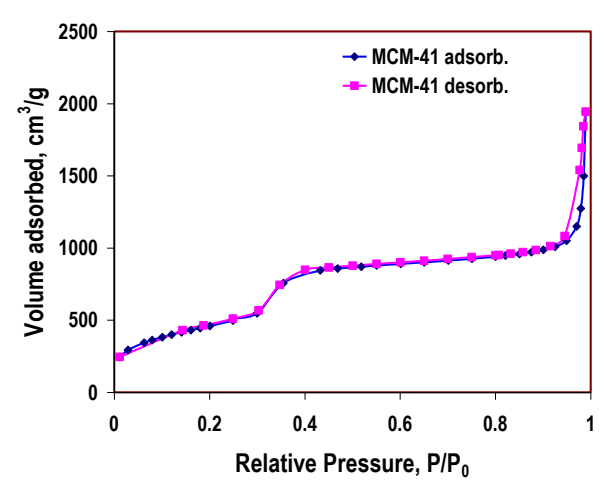


Fig.1. $\mathrm{N}_{2}$ adsorption/desorption isotherm of the MCM-41.

Figure 2 presents the linear plot of $1 /\left[V\left(P_{0} / P\right)\right.$ $1]$ as a function of $P / P_{0}$, required by BET equation, in the range of $0.05<P / P_{0}<0.20$ in Fig. 1 .

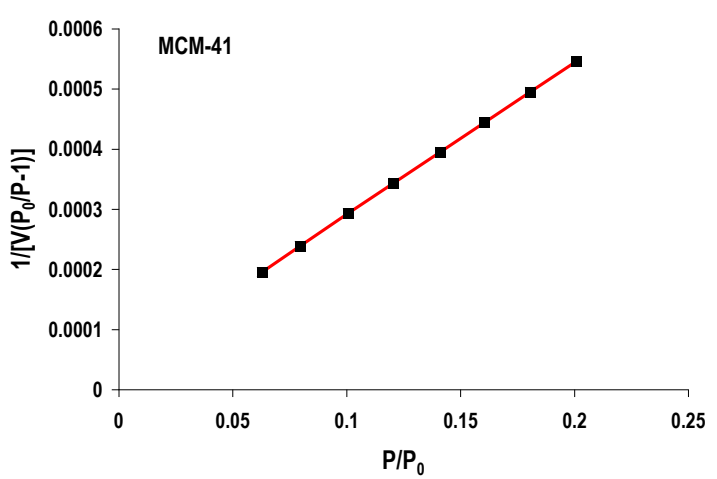

Fig.2. Multipoint BET plot for the specific surface area calculation.

The weight of the monolayer adsorbed gas $V_{m}$ and the BET constant $C$ were calculated using the values of the slope, $A$, and the $y$-intercept, I, determined from Fig. 2.

$$
\begin{aligned}
& V_{m}=\frac{1}{A+I} \\
& C=1+\frac{A}{I}
\end{aligned}
$$

The specific surface area of the MCM-41 was evaluated using the following equation:

$$
S_{B E T}=\frac{4.3532 \cdot V_{m}}{m}
$$

where $m$ is the weight of sample used for the measurement (in g). The calculated $V_{m}, C, S_{B E T}$ and pore diameter calculated by the BJH method are described in Table 1.

Table 1. The specific surface area of the MCM-41.

\begin{tabular}{|c|c|c|c|}
\hline $\begin{array}{c}V_{m}, \\
\mathrm{~cm}^{3} / \mathrm{g}\end{array}$ & $\begin{array}{c}\text { BET constant } \\
(\mathrm{C})\end{array}$ & $\begin{array}{c}S_{B E T}, \\
\mathrm{~m}^{2} / \mathrm{g}\end{array}$ & $\begin{array}{c}\text { BJH pore } \\
\text { diameter, } \\
\mathrm{nm}\end{array}$ \\
\hline 388.41 & 69.63 & 1690.81 & 2.7 \\
\hline
\end{tabular}

The XRD patterns of the MCM-41 supported catalysts in comparison with low-angle ones of the pure mesoporous silica MCM-41 are shown in Fig. 3 .

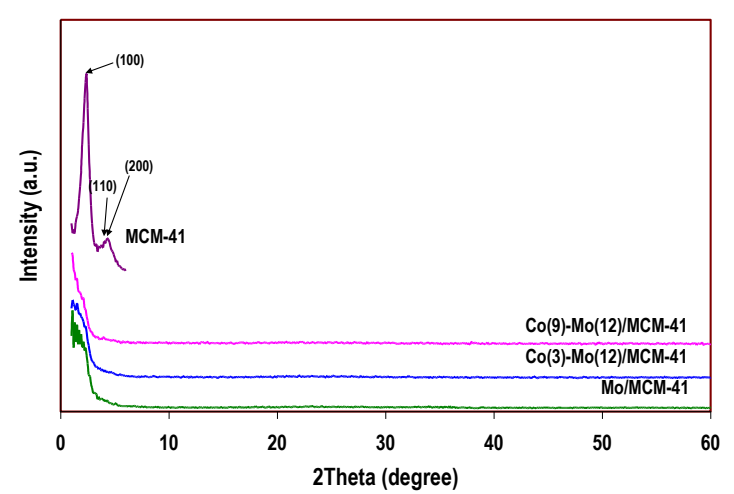

Fig.3. XRD patterns of the MCM supported CoMo catalysts and pure MCM-41.

The low-angle XRD pattern of the MCM-41 exhibits an intense peak corresponding to the (100) plane reflection at $2 \theta$ angle of $2.4^{\circ}$ and two weak peaks at 4.0 and $4.4^{\circ}$, which can be attributed to the diffraction of the (110) and the (200) planes, respectively. These peaks show the good long range ordered hexagonal structure of the synthesized material. From the low-angle XRD patterns of the Co-Mo catalysts, the disappearance of the characteristic peaks of the pure MCM-41 is observed, indicating loss of its long range order after loading the catalytic active components [4]. This fact suggests that the surface area, pore volume and pore size decrease significantly with loading the active components. On the other hand, the XRD patterns of the catalysts in the range of $10 \sim 60^{\circ}$ does not show any peaks corresponding to the catalytic active components, $\mathrm{CoO}$ and $\mathrm{MoO}_{3}$, indicating that the added active components are finely dispersed in the support, and thus particle sizes of the active phases are below the detection limit of the XRD instrument used. The good dispersion of the active phases in the support indicates that the MCM-41 supported CoMo catalysts have significantly high surface area. Also, this good dispersion suggests that MCM-41 can be used for the preparation of supported catalysts with high surface area and high dispersions. Even if the MCM-41 has lost its long range order 
due to the loading of the catalytic active components, it maintains its other initial properties such as high surface area and ordered mesoporous structure.

The test results of the catalytic performance of the MCM-41 supported catalysts for 1-octene hydrogenation are shown in Fig. 4.

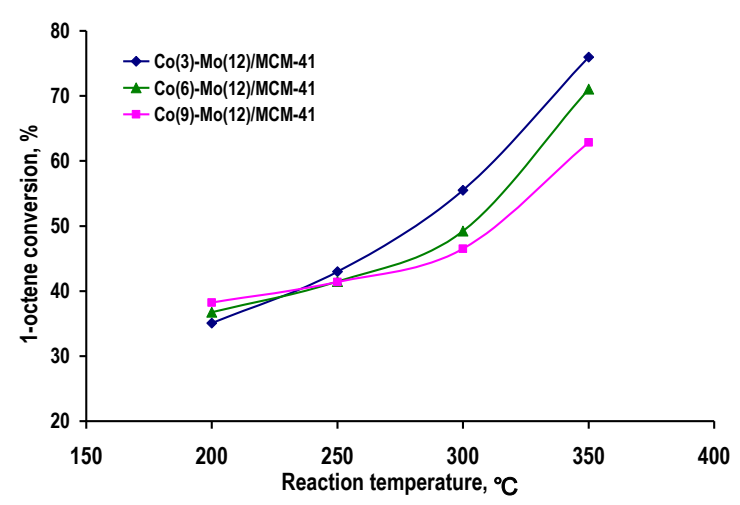

Fig.4. 1-octene conversion as a function of the reaction temperature in the presence of the MCM-41 supported Co-Mo catalysts.

From Fig. 4 it can be clearly seen that 1-octene conversion increases with the increase of the reaction temperature for the Co-Mo catalysts investigated. Moreover, the catalysts with higher $\mathrm{CoO}$ content show higher activity (up to $40 \%$ ) for 1 octene hydrogenation at reaction temperatures below $250^{\circ} \mathrm{C}$, but they show opposite results at reaction temperatures above $250^{\circ} \mathrm{C}$. Because there are different reactions that may take place in the presence of the Co-Mo/MCM-41 catalyst such as 1octene hydrogenation to n-octane and cracking of octane, we explain these results to be caused by the competitive reactions occurred on different active sites of the catalysts.

\section{Conclusions}

The mesoporous silica MCM-41 has high surface area, $\mathrm{S}_{\mathrm{BET}}=1690.81 \mathrm{~m}^{2} / \mathrm{g}$ and long range ordered hexagonal structure. The XRD patterns of the MCM-41 and the Co-Mo/MCM-41 catalysts show that metal species, $\mathrm{CoO}$ and $\mathrm{MoO}_{3}$, are finely dispersed in the MCM-41. Therefore, particle sizes of the active phases are below the detection limit of the XRD instrument. The good dispersion of the active phase in the support indicates that MCM-41 supported Co-Mo catalysts have significantly high surface area. All the investigated MCM-41 supported catalysts show an increase of the hydrogenation activity with the increase of the reaction temperature when the temperature ranges from 200 to $350^{\circ} \mathrm{C}$. The catalysts with higher $\mathrm{CoO}$ content show higher hydrogenation activity at reaction temperatures below $250^{\circ} \mathrm{C}$, but opposite results at reaction temperatures above $250^{\circ} \mathrm{C}$.

\section{Acknowledgments}

The authors thank scientific committee of international conference CHIMIA 2012 "New trends in applied chemistry" for the useful discussions.

\section{References}

* E-mail address: chol.hciu@yahoo.com;

**dciuparu@upg-ploiesti.ro

[1]. V. Voicu, C.R. Jang and D. Ciuparu, Buletinul UPG, Seria Tehnică, Vol. LXII, 3A, 13 (2010).

[2]. V. Voicu, I. Bolocan and D. Ciuparu, Rev. Chim. (Bucharest) 62, 12, 1206 (2011).

[3]. G.C. Suciu, in Ingineria prelucrării hidrocarburilor. Seria ingineria chimică, vol. 4, ed. Tehnică, Bucureşti, 1993, pp. 288-334.

[4]. G. Shi, D. Fang and J. Shen, Microporous and Mesoporous Materials 120, 339 (2009).

[5]. E. Rodríguez-Castellón, A. Jiménez-López and D. Eliche-Quesada, Fuel 87, 1195 (2008).

[6]. I. M. Angulo and E. Bouwman, Journal of Molecular Catalysis A: Chemical 175, 65 (2001).

[7]. http://www.cvt.uni-bayreuth.de/Forschung /116 Octen_en.php

[8]. B. Battsengel, L. Datsevich and A. Jess, Chem. Eng. Technol. 25, 6, 621 (2002)

[9]. D. Ciuparu, Y. Chen, S. Y. Lim, Y. H. Yang, G. L. Haller and L. Pfefferle, Journal of Physical Chemistry B, 108, 15565 (2004).

Submitted: April $23^{\text {th }} 2012$ Accepted in revised form: September $18^{\text {th }} 2012$ 